\title{
Endodontic Management of Radix Entomolaris: Case Report.
}

\author{
Dr. Dayanand Chole ${ }^{1}$, Dr. Kiran Maske ${ }^{2}$, Dr. Shashank Kundoor ${ }^{3}$, \\ Dr. Srinivas Bakle ${ }^{4}$, Dr. Neha Gandhi ${ }^{5}$, Dr. Rucha Deshpande ${ }^{6}$ \\ ${ }^{1}$ Professor and Head: Department of Conservative dentistry and Endodontics, P.D.U Dental College, Solapur \\ ${ }^{2}$ Post Graduate Student: Department Of Conservative Dentistry and Endodontics, PDU Dental College, Solapur \\ ${ }^{3,4}$ Reader: Department Of Conservative Dentistry and Endodontics, PDU Dental College, Solapur \\ ${ }^{5,6}$ Senior Lecturer: Department Of Conservative Dentistry and Endodontics, PDU Dental College, Solapur
}

\begin{abstract}
Mandibular molars exhibit varied root canal morphology which makes the endodontic treatment challenging. A mandibular first molar with additional buccal root (Radix paramolaris) and additional distolingual root (Radix Entomolaris) is an example of its varied anatomy. Success of endodontic treatment depends on proper identification and localization of all the canals, thorough chemo-mechanical preparation followed by three-dimensional obturation with hermetic seal. Failure of any of these steps may occur due to unusual tooth morphology. Hence, for a successful root canal therapy, clinician must be aware of the external and internal anatomic variations This report discusses endodontic treatment of mandibular molar with a radix entomolaris which is a rare macrostructure.
\end{abstract}

Keywords: Anatomic variations, endodontic treatment, mandibular molar, radix entomolaris.

\section{Introduction}

The treatment of entire root canal system is essential to maximize the possibility of obtaining success in the endodontic therapy. It is necessary for the clinician to have a thorough knowledge of the dental anatomy as well as of its variations. The majority of mandibular first molars have two roots, mesial and distal with two mesial and one distal canal ${ }^{2,3}$. Many variations in root canal systems have been described. Fabra-Campos reported the presence of three mesial canals while Stroner reported three distal canals ${ }^{4,5}$. The number of roots in permanent mandibular first molar may also vary. A major variant is the presence of three roots in mandibular first molar, first mentioned in the literature by Carabelli known as radix entomolaris located in distolingual position ${ }^{6}$.When located on mesiobuccal surface, the anomaly is known as radix paramolaris. The external morphology of this anomaly having additional lingual or buccal root, are described by Carlsen and Alexandersen. Radix entomolaris has a frequency of less than 5\% in white Caucasian, African, Eurasian and Indian populations while it appears to be commonly present in races of Mongoloid traits such as the Chinese, Eskimos, and Native American populations with a frequency of 5-30\%. Radix entomolaris has an occurrence of less than $5 \%$ in the Indian population and such cases are not routinely observed during dental procedures. ${ }^{8-11}$. Knowledge of such anatomic variation of root and root canals is essential during the treatment of the patients presenting with morphological diversities in their root canal anatomy. The aim of this paper is to report a case of Radix Entomolaris in mandibular first molar with a simultaneous ex vivo evaluation.

\section{Case Report}

A 34 -year-old female patient was referred to the Department of Conservative Dentistry and Endodontics, with the chief complaint of pain in lower right back region. An intraoral and radiographic examination revealed a deep carious lesion approaching pulp in the right mandibular first molar (fig1.) On radiographic examination, radiolucency was noted in the furcation area for which the patient was referred to The Department of Periodontics, where a secondary periodontal treatment after 3months was suggested for the same following endodontic treatment. Provisional diagnosis with 46 was made as chronic irreversible pulpitis. Treatment plan was decided as RCT with 46 followed by full crown.

Inferior alveolar nerve block anesthesia (2\% Lignocaine with 1:200000 epinephrine) was given. After anesthesia isolation was done with rubber dam, access cavity was prepared using an endo access bur and opening of pulp chamber was done and two mesial canal orifices (mesiobuccal,mesiolingual) and one distal canal orifice (distobuccal) were initially located. Another orifice was located on distolingual part of the pulpal floor on further exploration. The root canals orifices were enlarged using gates glidden drills (Mani Inc., Japan) for a straight line access and the shape of access cavity was modified from a triangular form to more trapezoidal form to better locate distolingual root. The root canals were explored with a K-file ISO number 15 and radiographic working length of the root canals were determined(fig2). Biomechanical preparation was carried out using the Pro Taper rotary files (Dentsply,Switzerland) in all the canals with intermittent irrigation using $2.5 \%$ sodium hypochlorite, $17 \%$ EDTA to remove smear layer and saline. After completion of biomechanical 
preparation, a closed dressing was given. On recall after a week, the patient was asymptomatic. The canals were irrigated with $1.2 \%$ chlorhexidine gluconate, warm saline and dried with paper points and obturation was done with corresponding protaper gutta-percha cones (Dentsply Maillefer) using Sealapex sealer (Dentsply, Maillefer). The access cavity was then sealed with light cure composite(3M ESPE) (fig3,fig4).

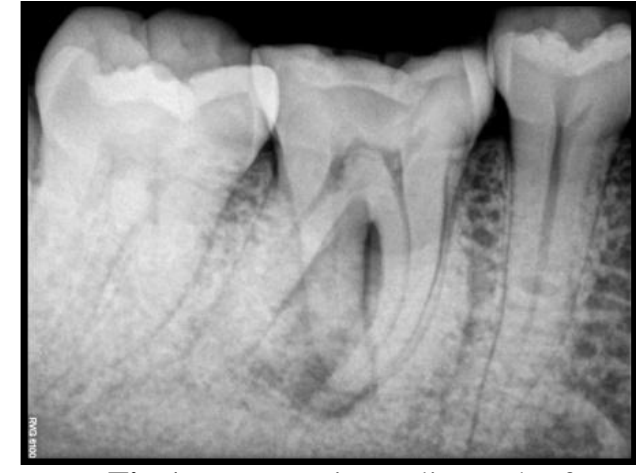

Fig.1 Preoperative radiograph of Radix with 46.

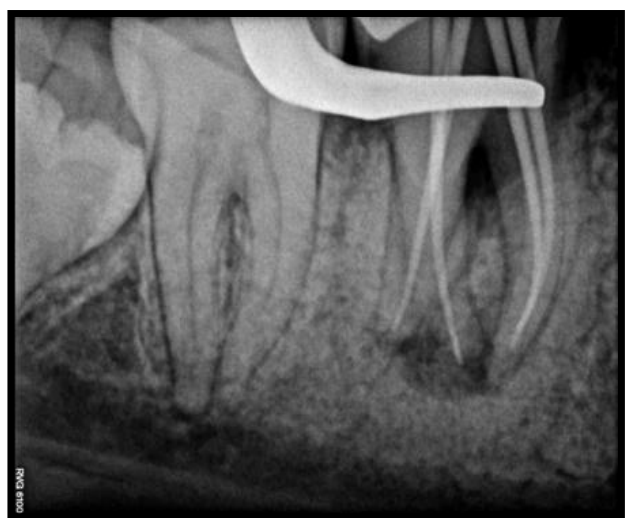

Fig.3 Master cone fit radiograph.

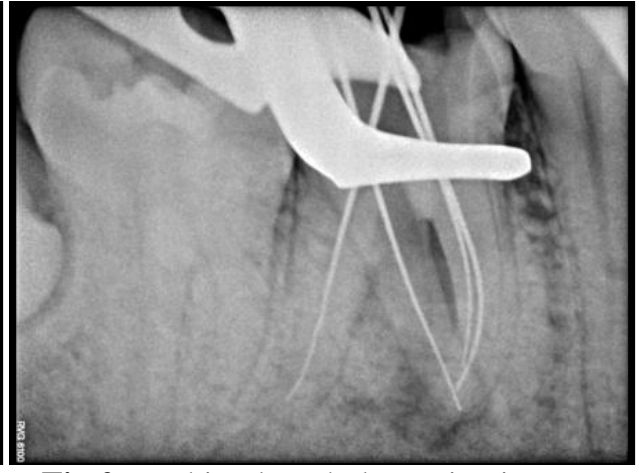

Fig.2 Working length determination radiograph.

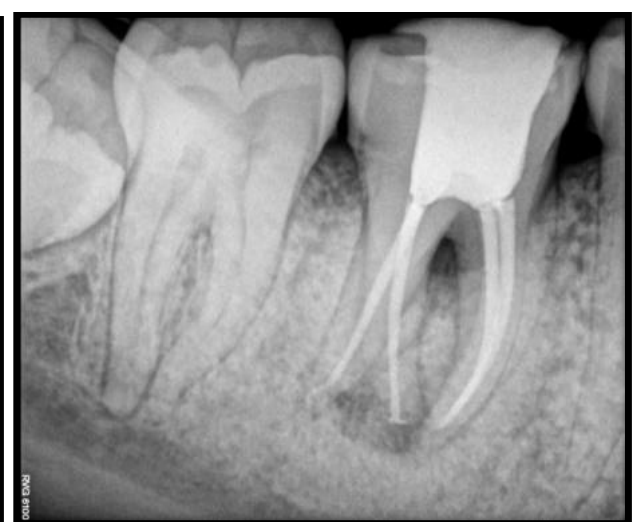

Fig.4 Post operative radiograph.

Etiology:

\section{Discussion}

The exact cause of radix entomolaris is still not known. Some authors say that it may be due to disturbance during odontogenesis or may be due to an atavistic gene.

\section{Prevelance:}

A supernumerary root can be found on the first, second and third mandibular molars, occurring least frequently on the second molar. Some studies reported a bilateral occurrence of radix entomolaris of 50$67 \%^{11,18}$. The presence of single radix entomolaris in mandibular first molar has been associated with determined ethnic groups. In Black populations, the maximum frequency is found to be $3-4 \%$ while in Caucasians and Indians the frequency less than $5 \%{ }^{10}$. In Chinese, Eskimos and American Indian population, studies have shown that radix entomolaris occurs in constancy ranging from 5\% to more than $30 \% .^{12}$. because of high frequency in these populations, Radix entomolaris is considered normal( eumorphic root morphology). In caucasians radix entomolaris is not common with maximum occurence from $3.4 \%$ to $4.2 \%{ }^{8,13}$. In eumorphic roots, racial genetic factors influenced the deepest expression of a particular gene which results in the most accentuates phenotypic manifestation ${ }^{14,15}$. Curzon suggested that a 'molar of roots' has a hight degree of genetic trace penetrance; its domain reflected in the fact of which the prevelance was similar in pure Eskimos and in misture of Eskimos and Caucasians.

Root canal configuration of mandibular first molar with two distal canals varies from $20 \%$ to $46 \%$ in different populations. ${ }^{16}$ The presence of three distal canals in mandibular first molar have been reported to be $1.7 \%$ in Indian population, $1.7 \%$ in Turkish population, $0.7 \%$ in Burmese population, $1.6 \%$ in Thai population, $0.2 \%$ in Senegalese population, and $3 \%$ in Sudanese population ${ }^{17 .}$ Bolk $^{19}$ has reported the presence of an additional root located at the buccal surface : Radix Paramolaris. This macrostructure is very rare and occurs less frequently than the radix entomolaris. The prevelance of radix paramolaris as observed by Visser ${ }^{20}$ was $0 \%$ for mandibular first molar, $0.5 \%$ for second molar and $2 \%$ for third molar. ${ }^{19}$ 


\section{Morphology}

The radix entomolaris is located distolingually, with its total or partial coronal third fixed to the distal root. The dimensions of radix entomolaris varied from a mature root with normal root length and canal to a small conical extension. Generally Radix entomolaris is smaller than mesial roots and distobuccal root with having pulp tissue within it. ${ }^{14}$ External appearance of radix entomolaris shows that the distal furcation is slightly less $(1 \mathrm{~mm})$ than the furcation between mesial and distal roots.

\section{Classification of radix entomolaris}

Carlsen\&Alexandersen $(1990)^{7}$ classified radix entomolaris(RE) into four different types based on the location of its cervical part:

Type A: the RE is located lingually to the distal root complex which has two cone-shaped macrostructures.

Type B: the RE is located lingually to the distal root complex which has one cone-shaped macrostructures.

Type C: the RE is located lingually to the mesial root complex.

Type AC: the RE is located lingually between the mesial and distal root complexes.

This classification allows proper identification of separated and non separated radix entomolaris cases.

De Moor et al. $(2004)^{21}$ classified radix entomolaris based on the curvature of the root or root canal:

Type 1: a straight root or root canal.

Type 2: a curved coronal third which becomes straighter in the middle and apical third.

Type 3: An initial curve in the coronal third of the root canal and a second buccally oriented curve beginning in the middle and continuing to the apical third.

Song JS et al. $(2010)^{22}$ further added two more newly defined variants of radix entomolaris

Small type: length shorter than half of the length of the distobuccal root.

Conical type: smaller than the small type and having no root canal within it.

\section{Clinical implication:}

Access cavity preparation should be modified usually from a triangular to a trapezoidal shape. The modification should be done following the dentinal map. Advanced diagnostic aids such as magnifying loupes or surgical microscope help in the better identification and visualization of all the canals. Using various instruments like endodontic explorer, path finder, DG 16 probe and micro-opener and the use of sodium hypochlorite for champagne effect would help in identification of anadditional orifice. A severe root inclination or canal curvature, particularly in the apical third of the root (as in a type III RE), can cause shaping aberrations such as straightening of the root canal or a ledge, resulting in root canal transportation and loss of working length. ${ }^{24}$ The use of flexible nickel-titanium rotary files allow a more centered preparation shape with restricted enlargement of the coronal canal third and orifice relocation. While treating RE, the knowledge of mean interorifice distances might help dentists to locate orifices and to achieve successful endodontic treatment. Tu et al. has reported that mean inter-orifice distances from the disto-lingual canal to the distobuccal, mesio-buccal and mesio-lingual canals of the permanent three-rooted mandibular molars were 2.7, 4.4 and $3.5 \mathrm{~mm}$, respectively. ${ }^{25}$

\section{Conclusion}

Understanding the variations in the root canal morphology is important for the successful outcome after conventional root canal therapy. A case of radix entomolaris may be challenging but can be easily diagnosed by a careful evaluation of pre-operative radiographs when taken at different angulations. A proper access preparation, and thorough examination of pulp chamber to locate and debride all canals is important. The initial diagnosis of radix entomolaris is important to facilitate the procedure during treatment and avoid the mislocation of any canal. A knowledge of such deviation and schematic treatment approach becomes mandatory for long term success in such cases.

\section{References}

[1]. Rayhani MF, Rahimi S, Shahi S. Root canal therapy of a mandibular first molar with five root canals: a case report. IEJ 2007;2(3):110-2

[2]. Vertucci FJ (1984) Root canal anatomy of the human permanent teeth. Oral Surg Oral Med Oral Pathol 58: 589-599. Barker BC, Parsons KC, Mills PR, Williams GL (1974) Anatomy of root canals. III. Permanent mandibular molars. Aust Dent J 19: 408-413.

[3]. Fabra-Campos H (1989) Three canals in the mesial root of mandibular first permanent molars: a clinical study. Int Endod J 22: 39 43. 
[4]. Stroner WF, Remeikis NA, Carr GB (1984) Mandibular first molar with three distal canals. Oral Surg Oral Med Oral Pathol 57: 554-557.

[5]. Carabelli G (1844) Systematisches Handbuch der Zahnheilkunde (2 edn). Braumuller und Seidel, Vienna, Italy. p114

[6]. Carlsen O, Alexandersen V (1990) Radix entomolaris: identification and morphology. Scand J Dent Res 98: 363-373. Curzon ME, Curzon JA (1971) Three-rooted mandibular molars in the Keewatin Eskimo. J Can Dent Assoc (Tor) 37: 71-72.

[7]. Turner CG 2nd (1971) Three-rooted mandibular first permanent molars and the question of American Indian origins. Am J Phys Anthropol 34:229-241.

[8]. Tratman EK (1938) Three-rooted lower molars in man and their racial distribution. British Dental Journal. 64: 264-274

[9]. Yew SC, Chan K (1993) A retrospective study of endodontically treated mandibular first molars in a Chinese population. J Endod 19: 471-473.

[10]. Walker T, Quakensbush LE. Three rooted lower first permanent molars in Hong Kong Chinese. Br Dent J. 1985; 159:298-9

[11]. Ferraz JA, Pecora JD. Three-rooted mandibular molars in patients of Mongolian , Caucasian and Negro origin. Braz Dent J.1993;3:113-7.

[12]. Reichart PA, Metah D. three- rooted permanent mandibular first molars in Thai. Community Dent Oral Epidemiol. 1981;9:191-2

[13]. Ribeiro FC, Consolaro A. Importancia clinica y anthropologica de la raiz distolingual en los molars inferiores permanents. Endodoncia. 1997; 15:72-8

[14]. Gulabivala K, Aung TH, Alavi A, Ng YL. Root and canal morphology of Burmese mandibular molars. Int Endod J. 2001 $\mathrm{Jul} ; 34(5): 359-70$.

[15]. Kottoor J, Sudha R, Velmurugan N. Middle distal canal of the mandibular first molar: a case report and literature review. Int Endod J. 2010 Aug;43(8):714-22.

[16]. Eelman R. Incidence of an accessory distal root on mandibular first permanent molars in Hispanic children. J Dent Child. 1986;53:122-3

[17]. Bolk L. Welcher Gebißreihe gehÖren die Molaren an? Z Morphol Anthropol. 1914;17:83-116.

[18]. Visser JB. Beitrag zur Kenntnis der menschlichen Zahnwurzelformen. Hilversum:Rotting;1948.p.49-72 21.De Moor RJ, Deroose CA, Calberson FL. The radix entomolaris in mandibular first molars: an endodontic challenge. IntEndod J 2004;37:789 99

[19]. Song JS, Choi HJ, Jung IY, Jung HS, Kim SO. The prevalence and morphologic classification of distolingual roots in the mandibular molars in a Korean population. J Endod 2010; 36: 653-657.

[20]. Gu Y1, Zhou P, Ding Y, Wang P, Ni L . Root canal morphology of permanent three-rooted mandibular first molars: Part IIIAnodontometric analysis. J Endod 2011; 37: 485-490.

[21]. Shikha Jaiswal, Sachin Gupta, Swati Chhokar, Vidushi Bahuguna Department of Conservative Dentistry \& Endodontics, Subharti Dental College, Meerut, Department of Conservative Dentistry Swami Vivekanand Subharti University, Meerut

[22]. KaraleR,Chikkamallaiah C, Hegde J.The Prevalence of Bilateral Three-Rooted Mandibular First Molar in Indian Population. Iran Endod J 2013;8(3):99-102. 